\title{
Efficacy and safety of pamidronate in Modic type 1 changes: study protocol for a prospective randomized controlled clinical trial
}

Stella Cecchetti ${ }^{1,2}$, Bruno Pereira ${ }^{3}$, Antoine Roche ${ }^{4}$, Christophe Deschaumes ${ }^{5}$, Dihya Abdi ${ }^{1}$, Emmanuel Coudeyre $^{6,2}$, Jean-Jacques Dubost ${ }^{1}$, Sylvain Mathieu, ${ }^{1,2}$, Sandrine Malochet-Guinamand ${ }^{1}$, Anne Tournadre , Marion Couderc ${ }^{1}$, Marielle Vayssade ${ }^{1}$, Coline Daron ${ }^{1,2}$ and Martin Soubrier ${ }^{1,2^{*}}$

\begin{abstract}
Background: Erosive degenerative disc disease, also known as Modic type 1 changes, is usually characterized by low back pain with an inflammatory pain pattern, as seen in spondyloarthropathies. Intravenous pamidronate has proven to be effective in patients with ankylosing spondylitis who are refractory to nonsteroidal antiinflammatory drugs, and in painful bone diseases in general, such as Paget's disease, fibrous dysplasia or vertebral fractures. We therefore hypothesize that pamidronate would be effective in treating low back pain associated with Modic type 1 changes.
\end{abstract}

Methods/Design: This study, called PEPTIDE (short for the French title "Etude Prospective sur l'Efficacité et la tolérance du PamidronaTe dans les dlscopathies Degeneratives Erosives"), will be a double-blind, randomized, placebo-controlled, parallel group, phase two clinical trial. A total of 48 patients will be recruited. These patients will be randomly assigned to one of the two groups, with 24 patients in each group: one group will be given pamidronate and the other a placebo. Pamidronate will be administered at a dose of $90 \mathrm{mg}$ per day for two days consecutively, and every patient, irrespective of treatment group, will be given paracetamol to maintain blinding by preventing druginduced fever. The primary outcome measure is a between-group difference of 30 points on a $100 \mathrm{~mm}$ Visual Analogue Scale (VAS) at three months. Secondary outcome measures are improvement in functional status and the drug's safety. Primary and secondary outcome measures will be assessed at each visit (inclusion, at six weeks, three months, and six months). If the primary goal is not attained, the patient will be offered a rigid or semi-rigid back brace, irrespective of the treatment group.

Discussion: To date, only local treatments, for example intradiscal corticosteroid therapy, lumbar arthrodesis or back braces have been studied in randomized, controlled trials, with controversial results. This trial is currently ongoing and, if conclusive, should provide physicians with an acceptable alternative to those treatments. The results should be publicly available in spring 2015.

Trial registration: ClinicalTrials.gov number, NCT01799616.

Keywords: Modic type 1 changes, Chronic pain, Pamidronate, Randomized Controlled Trial

\footnotetext{
* Correspondence: msoubrier@chu-clermontferrand.fr

${ }^{1}$ Rheumatology Department, Clermont-Ferrand University Hospital, G Montpied Hospital, 58 Montalembert Street, F-63003 Clermont-Ferrand, France

${ }^{2}$ Faculty of Medicine, University of Clermont 1, 28 Henri Dunant Square,

F-63001 Clermont-Ferrand, France

Full list of author information is available at the end of the article
} 


\section{Background}

In 1988, Modic et al. suggested a classification scheme for endplate changes associated with erosive degenerative disk disease (EDDD) at the lumbar spine. Type 1 is characterized on a magnetic resonance imaging (MRI) scan by low signal on T1 and increased signal on T2 images, indicating bony edema [1]. EDDD is mostly a French denomination for a type of non-infectious erosive disease of the spine, among others, such as crystal deposition disease, erosive discopathy in patients under chronic hemodialyses and rheumatic diseases with inflammatory discopathy. EDDD is the degenerative, or osteoarthritic, subcategory of noninfectious erosive disk diseases. Erosions are not an essential feature of Modic type 1 changes, but the two have often been associated, since studies have described a constant presence of Modic type 1 changes in EDDD [2]. Moreover, usually superficial erosions have been described as one of the elementary bone lesions in degenerative disk disease associated with Modic type 1 changes [3]. Since 'Modic type 1 changes' is supposedly a radiological definition and does not encompass the clinical aspect, it has been accepted for a long time, in France at least, that we speak of EDDD, recently changed to 'active discopathy'.

The correlation between Modic type 1 changes and back pain is still a matter of debate. There is however, to this date, far more evidence in favor of a real relationship between the two than otherwise. A 2008 systematic review [4] thus found 'a positive association between vertebral endplate signal changes (VESC, or Modic changes), and low back pain (LBP) in the majority of studies reporting on this subject', with Odds Ratios in the studies that reported a statistically significant positive association ranged between 2.0 and 19.9. Moreover, 'a positive association between VESC and LBP has not only been found in the majority of studies of patients with LBP from different countries, but also in the general and working populations. In other words, there is a considerable consistency in this association' [4].

Another 2008 review [5] confirmed the possibility of asymptomatic individuals with Modic changes but emphasized on its infrequency [6-8], and concluded that type 1 changes are likely to be inflammatory in origin and seem to be strongly associated with active low back symptoms and segmental instability, thus reflecting a state of active degeneration and biomechanical instability of the lumbar spine'. For an MRI classification, Modic changes are therefore usually considered a validated clinical finding; Toyone et al. observed that $73 \%$ of patients with type 1 changes had low back pain, making asymptomatic subjects much less common than those with type 2 changes (11\%) [6]. Modic type 1 changes have also been found to be specifically associated with the presence of low back pain [9], supporting the hypothesis that this early stage of the Modic disease is active [10]. Moreover, patients with Modic type 1 changes usually experience acute flares of previous common chronic lower back pain, usually with an inflammatory pattern [11]. Therefore, the clinical presentation of EDDDs mimics that of spondyloarthropathies (SpA), with consequent first-line treatment based on the use of nonsteroidal antiinflammatory drugs (NSAIDs) [12]. However, these treatments can be inadequate or even totally ineffective (at least $25 \%$ of patients are said to be refractory to NSAIDs), and sometimes poorly tolerated (gastroduodenal ulcers, arterial hypertension, and so forth) [13]. Corticosteroid therapy, which is not indicated for common low back pain, has been suggested for EDDDs by Maigne and Ballard, but over $50 \%$ of patients in the only open-label study experienced therapeutic failure [14].

Local treatments have been suggested, ranging from intradiscal cortisone injections to arthrodesis [15-20]. The results are, however, controversial $[21,22]$. These invasive procedures expose the patient to a risk of infection for intradiscal injections and to operating complications for arthrodesis [19].

Pamidronate, intravenous bisphosphonate with action on bone turnover, has shown some efficacy in open-label studies on spondyloarthropathies that are resistant to NSAIDs, whether on ankylosing spondylitis or SAPHO (Synovitis, Acne, Pustulosis, Hyperostosis, Osteitis) syndrome [22-31]. Although this efficacy in spondyloarthropathies remains a topic of discussion, it has nevertheless been clearly demonstrated for various types of bone pain (Paget's disease [32], fibrous dysplasia of bone [33] and vertebral compression $[34,35])$. Therefore, we conducted an open-label study on the efficacy of pamidronate in ten patients with EDDD in 2006, with conclusive results [36]. At one year, four patients deemed their overall improvement to be excellent ( 85 to $100 \%$ ), four to be good (70 to $85 \%)$ and two to be poor $(<55 \%)$. The inflammatory pain pattern disappeared as early as the first month in four patients and after one year in nine out of ten patients. Mean scores on the Visual Analogue Scale (VAS) showed gradual improvement, which was significant at six months $(35.1 \pm 30.2 \mathrm{~mm} ; p=0.05)$ and one year $(32.1 \pm 24 \mathrm{~mm} ; p=0.01)$. The improvement was quickly significant on the Quebec scale (a 20-item selfadministered instrument designed to assess the level of functional disability in individuals with back pain), at one month $(26 \pm 27.7 ; p=0.02)$ and at one year $(15.8 \pm$ $18 ; \mathrm{p}=0.001$ ). The mean Schober score, measuring lumbar flexion mobility, was unchanged.

The objective of this clinical trial is to demonstrate the efficacy of pamidronate in degenerative disc diseases by conducting a prospective, randomized, placebo-controlled study. Patients with inflammatory low back pain and a Modic type 1 change on their MRI, whose inclusion and 
exclusion criteria are detailed in Table 1, will be randomly assigned to one of two groups: one group will be given pamidronate and the other placebo. Pamidronate will be administered at a dose of $90 \mathrm{mg}$ per day for two days consecutively. The primary outcome measure is a betweengroup difference of 30 points on a $100 \mathrm{~mm}$ VAS at three months. Secondary outcome measures are improvement in functional status and the drug's safety. In case of failure at three months, it will be recommended that the patient, irrespective of the treatment initially received, wear a rigid or semi-rigid dorsolumbar brace, whose efficacy will be evaluated using the same criteria at six months to ensure the patient is at least partially relieved at the end of the study, provided that they had not used a brace before the start of the study.

\section{Methods and design}

\section{Study design and location}

PEPTIDE will be a double-blind, randomized, placebocontrolled on a 1:1 ratio, parallel group, phase two clinical trial. The endpoints will be measured at baseline, six weeks, three months and six months. In case of failure to alleviate pain with pamidronate at three months, a rigid back brace will be offered to all patients irrespective of the treatment group, and its efficacy will be assessed at six months. PEPTIDE will be conducted in the Rheumatology Department of Clermont-Ferrand University Hospital in France.

To maintain blinding, every patient regardless of the group they are in, will be given paracetamol to prevent pamidronate-induced fever insofar as is possible, and the product will only be labelled with the patient randomization number. Moreover, both the nurses and physicians from the rheumatology department responsible for administering the product and looking for side effects will be blinded to the participants' status, and the assessments will be performed by physicians from the Physical Medicine and Rehabilitation Department who are unaware of said side effects.

\section{Participants}

Participants are currently being recruited for this study from the Rheumatology and Physical Medicine and Rehabilitation Departments of Clermont-Ferrand University Hospital, and from the patients of local rheumatologists in private practice. The inclusion and exclusion criteria are described in Table 1.

\section{Approval}

All patients will provide their informed consent and the study will be conducted according to the principles of the Declaration of Helsinki. This protocol has been approved by the Sud-Est VI Ethics Committee, which is affiliated with Clermont-Ferrand University Hospital, and by the French National Agency for Medicines and Health Products Safety (ANSM).

\section{Randomization}

The randomization list will be drawn up by the methodologist in charge of the project before the start of the

Table 1 Eligibility criteria

\begin{tabular}{|c|c|}
\hline Inclusion criteria & Exclusion criteria \\
\hline - Aged between 18 and 60 years & - Static disorders of the spine \\
\hline \multirow{3}{*}{$\begin{array}{l}\text { - Low back pain with an inflammatory pattern (at least one of three } \\
\text { characteristics: waking at night due to pain, morning stiffness for longer } \\
\text { than } 60 \text { minutes, maximal pain on morning) }\end{array}$} & $\begin{array}{l}\text { - Contraindication to pamidronate (hypocalcaemia, severe kidney } \\
\text { failure or allergy) }\end{array}$ \\
\hline & - Underage patients, patients subject to legal protections \\
\hline & - Previous treatment with bisphosphonates \\
\hline - Daily pain for at least three months & - Pregnancy \\
\hline - VAS for pain $>40 / 100$ in the last 48 hours & - Local or general infection \\
\hline \multirow[t]{2}{*}{ - Lack of efficacy, intolerance, or contraindication to NSAIDs } & - Previous disc surgery \\
\hline & - Systemic corticosteroid therapy in the last month \\
\hline - Lack of efficacy of a rigid or semi-rigid back brace & - Epidural or facet joint corticosteroid injection in the last month \\
\hline $\begin{array}{l}\text { - Modic } 1 \text { disc disease (diagnosed on MRI and confirmed by a } \\
\text { trained radiologist) }\end{array}$ & - History of septic spondylodiscitis \\
\hline \multirow[t]{2}{*}{ - Dental check-up within the last six months } & - Ankylosing spondylitis \\
\hline & - Low back pain associated with radiculalgia \\
\hline \multirow[t]{3}{*}{ - Signed informed consent form } & - Active psychiatric disorder \\
\hline & - Inability to read or understand French \\
\hline & $\begin{array}{l}\text { - Body temperature greater than } 38^{\circ} \mathrm{C} \text { (fever) or erythrocyte sedimentation } \\
\text { rate greater than } 20 \mathrm{~mm} / \text { hour }\end{array}$ \\
\hline
\end{tabular}


trial; this stratified randomization by sex and age (18 to 40 years, 40 to 50 years, and 50 to 60 years) will be carried out to balance the group sizes using a computergenerated allocation sequence with a block size of four; this will make it possible to monitor the eligibility of patients and transfer information on the randomization to the investigator, and possibly other correspondents.

\section{Description of the intervention}

The study product is a $10 \mathrm{ml}$ vial of disodium pamidronate $9 \mathrm{mg} / \mathrm{ml}$, in a concentrated solution to be diluted in $500 \mathrm{ml}$ of $0.9 \%$ sodium chloride solution, for slow intravenous infusion. It will be administered at the dose of $90 \mathrm{mg}$ per day, for two days consecutively (for a total dose of $180 \mathrm{mg}$ ), as a slow intravenous infusion as in our pilot study [36]. We chose this administration pattern following Sayag-Boukris et al. [27] and Solau-Gervais et al.'s [31] method of treatment in SAPHO syndrome $(60 \mathrm{mg}$ each day, for three days consecutively), but divided the total dose of $180 \mathrm{mg}$ between two days. We estimated that this would reduce the length of stay, and knew from our pilot study that $90 \mathrm{mg}$ a day is usually well tolerated.

In the placebo group, the product used is a $500 \mathrm{ml} \mathrm{bag}$ of $0.9 \%$ sodium chloride solution.

In case of therapeutic failure at three months, the brace offered to patients will be a rigid or semi-rigid, lumbar or dorsolumbar brace custom made by the Physical Medicine and Rehabilitation Department.

\section{Outcome measures}

The primary outcome measure will be the difference between D0 and D90 $[16,20,22]$ in spinal pain assessed by VAS [36] between the treatment group and the placebo group (with a standard deviation of pain variation assessed by VAS set at $30[19,36]$.

The secondary outcome measures will be the differences at three months between the treatment group and the placebo group in: the French adaptation of the Roland-Morris Low Back Pain Questionnaire (EIFEL), Dallas and Fear Avoidance Beliefs Questionnaire (FABQ) scores, the McMaster Toronto Arthritis Patient Preference Disability Questionnaire (MacTar) and the Minimum Clinically Important Improvement/Patient Acceptable Symptom State (MCII/PASS) questionnaire [37-40]; measurements of finger-to-floor distance and the Schober test; clinical signs of spinal inflammation, with assessment of the number of nighttime awakenings and the duration and severity of morning stiffness on a VAS; and safety, with the number and severity of side effects, physical or biological, such as hypocalcemia or renal toxicity by dosages of serum calcium and creatinine.

Outcomes will also be measured at six weeks as an interim evaluation, and at six months as follow up. Table 2 summarizes the data-collection schedule.
Table 2 Outcome measures at baseline, interim assessment, three months and follow-up

\begin{tabular}{|c|c|c|c|c|}
\hline & Baseline & $\begin{array}{c}\text { Interim } \\
\text { assessment - } \\
\text { six weeks }\end{array}$ & $\begin{array}{l}\text { Three } \\
\text { months }\end{array}$ & $\begin{array}{l}\text { Follow up - } \\
\text { six months }\end{array}$ \\
\hline Informed consent & $x$ & & & \\
\hline $\begin{array}{l}\text { Inclusion and exclusion } \\
\text { criteria }\end{array}$ & $x$ & & & \\
\hline Demographic data & $x$ & & & \\
\hline $\begin{array}{l}\text { Medical and surgical } \\
\text { history }\end{array}$ & $x$ & & & \\
\hline Adverse effects & & $x$ & $x$ & $x$ \\
\hline Current daily treatment & $x$ & $x$ & $x$ & $x$ \\
\hline Dental status & $x$ & $x$ & $x$ & $x$ \\
\hline Routine dental visit & $x$ & & & \\
\hline Physical examination & $x$ & $x$ & $x$ & $x$ \\
\hline $\begin{array}{l}\text { Blood test (CBC, } \\
\text { hs-CRP, serum calcium, } \\
\text { serum creatinine, ESR, } \\
\text { vitamin D, PTH, CTX, } \\
\text { osteocalcin) }\end{array}$ & $x$ & $x$ & $x$ & $x$ \\
\hline Pain on $100 \mathrm{~mm}$ VAS & $x$ & $x$ & $x$ & $x$ \\
\hline EIFEL score & $x$ & $x$ & $x$ & $x$ \\
\hline FABQ score & $x$ & $x$ & $x$ & $x$ \\
\hline Dallas score & $x$ & $x$ & $x$ & $x$ \\
\hline MacTar score & $x$ & $x$ & $x$ & $x$ \\
\hline MCII/PASS score & & $x$ & $x$ & $x$ \\
\hline Finger-to-floor distance & $x$ & $x$ & $x$ & $x$ \\
\hline Schober's test & $x$ & $x$ & $x$ & $x$ \\
\hline $\begin{array}{l}\text { Number of nightly } \\
\text { awakenings }\end{array}$ & $x$ & $x$ & $x$ & $x$ \\
\hline $\begin{array}{l}\text { Severity of MS } \\
\text { (100 mm VAS) }\end{array}$ & $x$ & $x$ & $x$ & $x$ \\
\hline Duration of MS (min) & $x$ & $x$ & $x$ & $x$ \\
\hline
\end{tabular}

CBC, complete blood count; CTX, C-terminal telopeptide; EIFEL: French adaptation of the Roland-Morris Low Back Pain Questionnaire; ESR: erythrocyte sedimentation rate; FABQ: Fear Avoidance Beliefs Questionnaire; hs-CRP: high-sensitivity C-reactive protein; MacTar: McMaster Toronto Arthritis Patient Preference Disability Questionnaire; MCII/PASS: Minimum Clinically Important Improvement/ Patient Acceptable Symptom State; MS: morning stiffness; PTH: parathyroid hormone: VAS: visual analogue scale.

\section{Statistical considerations}

\section{Sample size estimation}

As the objective of this study is to show the efficacy of treatment with pamidronate on spinal pain attributed to Modic inflammatory disc disease, the justification of sample size estimation was based on the comparison of pain variation at three months, assessed using a VAS in the two randomization groups.

Therefore, considering type I and type II errors of 5\% (two-sided) and 10\%, respectively, 22 patients per group are needed to demonstrate a minimum difference of 30 points on the VAS scale of 0 to 100. As some subjects 
may be lost to follow up, 24 patients per group will be included.

\section{Statistical analysis}

Intention-to-treat analysis will be conducted; all statistical tests will be considered for a type I error $\alpha$ of $5 \%$.

Continuous variables will be presented as means and standard deviations, provided that their distribution is normal (Shapiro-Wilk test if needed [41]), or as medians, quartiles and extrema. Categorical parameters will be expressed as the number of subjects and associated percentages.

The patients will be described and compared between groups at inclusion using the following variables: fulfilment of eligibility criteria, epidemiological and clinical characteristics, and previous treatments.

As the primary outcome is variation in pain scored by the VAS, the randomization groups will be compared using a Student's $t$-test or Mann-Whitney test if appropriate. Homoscedasticity will be tested using the FisherSnedecor test.

The between-group comparisons at 1.5, 3 and 6 months for the other outcome measures will be considered using standard tests, as has been described for the primary outcome measure of quantitative variables (notably EIFEL, Dallas, FABQ, finger-to-floor distance and Schober's test), the Chi2 test or, where applicable, Fisher's exact test for the qualitative variables. These between-group comparisons will be made systematically without adjustment, and by adjusting for factors whose distribution could be imbalanced between groups despite the randomization or due to clinical relevance (including analgesic use, treatments (and modifications) and other co-interventions during the study, such as physiotherapy). To measure the changes in the variables collected over the different visit time-points, a longitudinal data analysis will be conducted via ANOVA (ANalysis Of Variance) for repeated measures or the Friedman test (if ANOVA conditions are not fulfilled), followed by a post-hoc test and mixed models to take into account within- and between-patient variability. The intragroup comparisons, conducted secondarily, will be implemented via paired Student's $t$-test or Wilcoxon test for the quantitative variables, and the Stuart-Maxwell test for the qualitative variables. Due to multiple comparisons envisaged at these three time-point evaluations, the inflation of type I error will be taken into account for each additional endpoint (Bonferroni adjustment should not be too conservative with only three time-points). The rate of subjects lost to follow up at three months is considered to be minor; the inclusion of 24 subjects is planned, while 22 patients should be necessary. In order to assess the problem caused by missing longitudinal data, estimation methods developed by Verbeke and
Molenberghs [42] will be considered. For other missing data, if the frequency of missing data is $>5 \%$, an additional analysis will be performed using the multiple imputation method (Stata's mi command software [43]).

\section{Discussion}

The treatment options for Modic type 1 disc diseases remain quite limited; invasive local treatments, such as intradiscal injections of cortisone derivatives or spinal arthrodesis, have generated controversial results [21,22], and the brace remains a last-resort solution for patients who wish to maintain some mobility and often consider it cumbersome and unsightly.

There are, to date, no published controlled trials involving pamidronate in EDDD. The results from our pilot study (an open-label study with ten subjects) were encouraging [36], and therefore we hypothesized, in light of this pilot study and the widespread use of pamidronate in painful bone diseases, that pamidronate could be effective in relieving EDDD-induced pain. However, the efficacy of pamidronate in this condition clearly required further investigation in a prospective, blinded, randomized controlled trial. Subject recruitment began in January 2013 and will continue until the end of December 2014, with the results made available in March 2015.

Regarding safety concerns, vitamin D blood levels will be measured before the product is administered and patients will be given vitamin $\mathrm{D}$ supplementation accordingly prior to treatment [44]. Every patient will also be examined by the dentist affiliated with the study to look for, and if necessary treat, contraindications to intravenous bisphosphonates.

All studies include biases, and we have taken several steps to limit those that could arise in this study; as pamidronate can cause fever and flu-like syndromes, the patient will be included by one physician and evaluated by another. In addition, to minimize this effect, patients from both groups will receive $1 \mathrm{~g}$ of paracetamol prior to the infusion and $1 \mathrm{~g}$ of paracetamol every 8 hours for 48 hours. To guarantee the double-blind and prevent biases in monitoring and measurement, physicians from the Rheumatology Department will be responsible for administering the product and monitoring the side effects (such as hyperthermia in cases of patients receiving pamidronate despite the administration of paracetamol, which would result in unblinding for both the patient and physician), and physicians, physiotherapists and occupational therapists from the Physical Medicine and Rehabilitation Department will be responsible for assessments (D0, D45, D90 and D180). In addition, and again to guarantee the blinding for the patient, the products administered intravenously will be identified not by the product name but by the patient's randomization number, and will be prepared by the hospital pharmacy so 
that the nurses performing the infusions will not know which product is infused to the patient. Treatment changes over the six months of follow up will be recorded and, to prevent a recall bias, each patient will be given a diary including a table to be completed following each change in his or her standard treatment. Finally, an experienced radiologist affiliated with the study and specializing in osteoarticular diseases is responsible for confirming each radiological diagnosis of Modic type 1 disc disease on an MRI scan. Concerning the sample size estimation, the assumption of our protocol is that the standard-deviation of the difference (test versus control) in change scores (initial versus final) is the same as the previous standard-deviation of the change score found for treated patients in the open pilot study [36]. Therefore, sample size estimation is based on previous works, which could be considered heterogeneous for the standard-deviation of the change score. In our pilot study [36], the standard-deviation of VAS was 19.1 at baseline, 22.7 at three months and 24.1 for change score. As standard-deviation equals 30, our estimation appears near to the expected results and overestimates the value obtained in the pilot study. Nevertheless, blinded studies have a smaller effect which may not be captured by the standard-deviation. Moreover, the statistical power was voluntarily more important than $80 \%$ (1- $\beta$ fixed equals $90 \%)$. Concerning the statistical approach, the primary outcome analysis will be pain-VAS difference at three months using a Student's $t$-test if normally distributed and a Mann-Whitney test if not. In the secondary outcome analysis, a multivariate situation should be proposed using a linear regression model to take adjustment factors into account. Adjustments may threaten the randomized nature of the study. To further ensure the randomization of the study, a random-effect model, considering block as a random effect could be proposed.

\section{Trial status}

PEPTIDE is ongoing and currently recruiting.

\begin{abstract}
Abbreviations
ANOVA: ANalysis Of Variance; CBC: complete blood count; CTX: C-terminal telopeptide; EDDD: erosive degenerative disc disease; EIFEL: French adaptation of the Roland-Morris Low Back Pain Questionnaire; ESR: erythrocyte sedimentation rate; FABQ: Fear Avoidance Beliefs Questionnaire; hs-CRP: high-sensitivity C-reactive protein; LBP: low back pain; MacTar: McMaster Toronto Arthritis Patient Preference Disability

Questionnaire; MCII/PASS: Minimum Clinically Important Improvement/ Patient Acceptable Symptom State; MRI: magnetic resonance imaging; MS: morning stiffness; NSAIDs: nonsteroidal antiinflammatory drugs; PEPTIDE: short for the French title "Etude Prospective sur l'Efficacité et la tolérance du PamidronaTe dans les dlscopathies Degeneratives Erosives": PTH: parathyroid hormone; SAPHO: Synovitis Acne Pustulosis Hyperostosis Osteitis; VAS: visual analogue scale; VESC: vertebral endplate signal changes.
\end{abstract}

\section{Competing interests}

The authors declare that they have no conflicts of interest.

\section{Authors' contributions}

MS: conception and design, data collection, analysis and interpretation, manuscript writing, critical revision and final approval of the manuscript. SC: conception and design, data collection, analysis and interpretation,

manuscript writing, critical revision and final approval of the manuscript. DA: design, data collection and analysis, critical revision and final approval of the manuscript. BP: conception, data analysis, manuscript writing, critical revision and final approval of the manuscript. CDa: data collection, critical revision and final approval of the manuscript. MV: data collection, critical revision and final approval of the manuscript. EC: design, data collection, critical revision and final approval of the manuscript. SM: conception and design, data collection, critical revision and final approval of the manuscript. SMG: data collection, critical revision and final approval of the manuscript. AT: data collection, critical revision and final approval of the manuscript. MC: data collection, critical revision and final approval of the manuscript. JJD: data collection, critical revision and final approval of the manuscript. AR: data analysis, critical revision and final approval of the manuscript. CDe: data collection, critical revision and final approval of the manuscript. All authors read and approved the final manuscript.

\section{Acknowledgements}

PEPTIDE is financially supported by the Regional Hospital Clinical Research Programme.

\section{Author details}

${ }^{1}$ Rheumatology Department, Clermont-Ferrand University Hospital, G Montpied Hospital, 58 Montalembert Street, F-63003 Clermont-Ferrand, France. ${ }^{2}$ Faculty of Medicine, University of Clermont 1, 28 Henri Dunant Square, F-63001 Clermont-Ferrand, France. ${ }^{3}$ Biostatistics Unit (Clinical Research and Innovation Department), Clermont-Ferrand University Hospital, 58 Montalembert Street, G Montpied Hospital, F-63003 Clermont-Ferrand, France. ${ }^{4}$ Radiology Department A, Clermont-Ferrand University Hospital, G Montpied Hospital, 58 Montalembert Street, F-63003 Clermont-Ferrand, France. ${ }^{5}$ Oral Surgery Department, Clermont-Ferrand University Hospital, 28 Henri Dunant Square, G Montpied Hospital, INSERM, U1107, F-63000 Clermont-Ferrand, France. ${ }^{6}$ Physical Medicine and Rehabilitation Department, Clermont-Ferrand University Hospital, 58 Montalembert Street, G Montpied Hospital, F-63003

Clermont-Ferrand, France.

Received: 2 August 2013 Accepted: 21 March 2014

Published: 9 April 2014

\section{References}

1. Modic MT, Masaryk TJ, Ross JS, Carter JR: Imaging of degenerative disk disease. Radiology 1988, 168:177e86.

2. Champsaur P, Parlier-Cuau C, Juhan V, Daumen-Legré V, Chagnaud C, Lafforgue $P$, Laredo JD, Kasbarian M: Differential diagnosis of infective spondylodiscitis and erosive degenerative disk disease. J Radio/ 2000 May, 81:516-522.

3. Bordet B, Borne J, Fantino O, Bousquet J-C, Coillard S: Analyse IRM selon Modic: intérêt dans les lombalgies. In Résonances Européennes du Rachis 2005, 13:1650-1652.

4. Jensen TS, Karppinen J, Sorensen JS, Niinimäki J, Leboeuf-Yde C: Vertebral endplate signal changes (Modic change): a systematic literature review of prevalence and association with non-specific low back pain. Eur Spine J 2008 Nov, 17:1407-1422.

5. Rahme R, Moussa R: The modic vertebral endplate and marrow changes: pathologic significance and relation to low back pain and segmental instability of the lumbar spine. AJNR Am J Neuroradiol 2008 May, 29:838-842

6. Toyone T, Takahashi K, Kitahara H, Yamagata M, Murakami M, Moriya H: Vertebral bone-marrow changes in degenerative lumbar disc disease: an MRI study of 74 patients with low back pain. J Bone Joint Surg Br 1994, 76:757-764.

7. Weishaupt D, Zanetti M, Hodler J, Boos N: MR imaging of the lumbar spine: prevalence of intervertebral disk extrusion and sequestration, nerve root compression, end plate abnormalities, and osteoarthritis of the facet joints in asymptomatic volunteers. Radiology 1998, 209:661-666.

8. Kjaer P, Korsholm L, Bendix T, Sorensen JS, Leboeuf-Yde C: Modic changes and their associations with clinical findings. Eur Spine J 2006, 15:1312-1319. 
9. Kjaer P, Leboeuf-Yde C, Korsholm L, Sorensen JS, Bendix T: Magnetic resonance imaging and low back pain in adults: a diagnostic imaging study of 40-year-old men and women. Spine 2005, 30:1173e80.

10. Revel M: IRM et lombalgies. Réflexions Rhumatologiques 2004, 69:29.

11. Bailly F, Maigne JY, Genevay S, Marty M, Gandjbakhch F, Rozenberg S, Foltz $\checkmark$ : Inflammatory pain pattern and pain with lumbar extension associated with Modic 1 changes on MRI: a prospective case-control study of 120 patients. Eur Spine J 2014, 23:493-497.

12. Nguyen C, Bendeddouche I, Sanchez K, Jousse M, Papelard A, Feydy A, Revel M, Poiraudeau S, Rannou F: Assessment of ankylosing spondylitis criteria in patients with chronic low back pain and vertebral endplate Modic I signal changes. J Rheumatol 2010 Nov, 37:2334-2339.

13. Revel M, Poiraudeau S, Lefèvre-Colau MM, Mayoux-Benhamou MA: La discopathie destructrice rapide. Rev Rhum 2000, 67:266-269.

14. Maigne JY, Ballard M: Y'a t'il des signes cliniques de discopathie inflammatoire lombaire? Revue de Médecine Vertébrale 2004, 13:12-14.

15. Beaudreuil J, Dieude P, Poiraudeau S, Revel M: Disabling chronic low back pain with Modic type $1 \mathrm{MRI}$ signal: Acute reduction in pain with intradiscal corticotherapy. Ann Phys Rehabil Med 2012 Apr, 55:139-147.

16. Buttermann GR: The effect of spinal steroid injections for degenerative disc disease. Spine J 2004, 4:495-505

17. Fayad F, Lefevre-Colau MM, Rannou F, Quintero N, Nys A, Macé Y, Poiraudeau S, Drapé JL, Revel M: Relation of inflammatory modic changes to intradiscal steroid injection outcome in chronic low back pain. Eur Spine J 2007 Jul, 16:925-931.

18. Vital JM, Gille O, Pointillart V, Pedram M, Bacon P, Razanabola F, Schaelderle C, Azzouz S: Course of Modic 1 six months after lumbar posterior osteosynthesis. Spine (Phila Pa 1976) 2003, 28:715-720.

19. Blondel B, Tropiano P, Gaudart J, Huang RC, Marnay T: Clinical results of lumbar total disc arthroplasty in accordance with Modic signs, with a 2year-minimum follow-up. Spine (Phila Pa 1976) 2011, 36:2309-2315.

20. Hanley EN Jr, David SM: Lumbar arthrodesis for the treatment of back pain. J Bone Joint Surg Am 1999 May, 81:716-730.

21. Staal JB, de Bie RA, de Vet HC, Hildebrandt J, Nelemans P: Injection therapy for subacute and chronic low back pain: an updated Cochrane review. Spine (Phila Pa 1976) 2009, 34:49-59.

22. Maksymowych WP, Jhangri GS, Leclercq S, Skeith K, Yan A, Russell AS: An open study of pamidronate in the treatment of refractory ankylosing spondylitis. J Rheumatol 1998 Apr, 25:714-717.

23. Maksymowych WP, Lambert R, Jhangri GS, Leclerca S, Chiu P, Wong B, Aaron S, Russell AS: Clinical and radiological amelioration of refractory peripheral spondyloarthritis by pulse intravenous pamidronate therapy. J Rheumatol 2001 Jan, 28:144-155.

24. Maksymowych WP, Jhangri GS, Fitzgerald AA, LeClerca S, Chiu P, Yan A, Skeith KJ, Aaron SL, Homik J, Davis P, Sholter D, Russell AS: A six-month randomized, controlled, double-blind, dose-response comparison of intravenous pamidronate ( $60 \mathrm{mg}$ versus $10 \mathrm{mg}$ ) in the treatment of nonsteroidal anti-inflammatory drug-refractory ankylosing spondylitis. Arthritis Rheum 2002 Mar, 46:766-773.

25. Haibel H, Brandt J, Rudwaleit M, Soerensen H, Sieper J, Braun J: Treatment of active ankylosing spondylitis with pamidronate. Rheumatology (Oxford). 2003 Aug, 42:1018-1020.

26. Cairns AP, Wright SA, Taggart AJ, Coward SM, Wright GD: An open study of pulse pamidronate treatment in severe ankylosing spondylitis, and its effect on biochemical markers of bone turnover. Ann Rheum Dis 2005, 64:338-339.

27. Sayag-Boukris V, Loussadi I, Cormier C, Laroche F, Menkes CJ, Kahan A: Efficacy of pamidronate in the treatment of SAPHO syndrome. Arthritis Rheum 1998, 41:S114.

28. Guignard S, Job-Deslandre C, Sayag-Boukris V, Kahan A: Pamidronate treatment in SAPHO syndrome. Joint Bone Spine 2002 Jun, 69:392-396.

29. Amital $H$, Applbaum $Y H$, Aamar S, Daniel N, Rubinow A: SAPHO syndrome treated with pamidronate: an open-label study of 10 patients. Rheumatology (Oxford) 2004, 43:658-661.

30. Soubrier M, Dubost JJ, Ristori JM, Sauvezie B, Bussière JL: Pamidronate in the treatment of diffuse sclerosing osteomyelitis of the mandible. Oral Surg Oral Med Oral Pathol Oral Radiol Endod 2001 Dec, 92:637-640.

31. Solau-Gervais E, Soubrier M, Gerot I, Grange L, Puechal X, Sordet C, Sibilia J, Duquesnoy $B$ : The usefulness of bone remodelling markers in predicting the efficacy of pamidronate treatment in SAPHO syndrome. Rheumatology (Oxford) 2006 Mar, 45:339-342.
32. Vasireddy S, Talwalkar A, Miller H, Mehan $\mathrm{R}$, Swinson DR: Patterns of pain in Paget's disease of bone and their outcomes on treatment with pamidronate. Clin Rheumatol 2003 Dec, 22:376-380.

33. Chapurlat RD: Medical therapy in adults with fibrous dysplasia of bone. J Bone Miner Res 2006 Dec, 21:P114-P119.

34. Gangji $\bigvee$, Appelboom T: Analgesic effect of intravenous pamidronate on chronic back pain due to osteoporotic vertebral fractures. Clin Rheumatol. 1999, 18:266-267.

35. Slobodin G, Rosner I, Feld J, Rimar D, Rozenbaum M, Boulman N, Odeh M: Pamidronate treatment in rheumatology practice: a comprehensive review. Clin Rheumatol 2009 Dec, 28:1359-1364.

36. Poujol D, Ristori JM, Dubost JJ, Soubrier M: Efficacy of pamidronate in erosive degenerative disk disease: A pilot study. Joint Bone Spine 2007 74:663-664

37. Coste J, Le Parc JM, Berge E, Delecoeuillerie G, Paolaggi JB: French validation of a disability rating scale for the evaluation of low back pain (EIFEL questionnaire). Rev Rhum Ed Fr 1993 May, 60:335-341.

38. Marty M, Blotman F, Avouac B, Rozenberg S, Valat JP: Validation of the French version of the Dallas pain questionnaire in chronic low back pain patients. Reu Rheum Engl Ed 1 1998, 8:65.

39. Sanchez K, Papelard A, Nguyen C, Bendeddouche I, Jousse M, Rannou F, Revel M, Poiraudeau S: McMaster-Toronto Arthritis Patient Preference Disability Questionnaire sensitivity to change in low back pain: influence of shifts in priorities. PLoS One 2011, 6:e20274.

40. Tubach F, Ravaud P, Beaton D, Boers M, Bombardier C, Felson DT, van der Heijde D, Wells G, Dougados M: Minimal clinically important improvement and patient acceptable symptom state for subjective outcome measures in rheumatic disorders. J Rheumato/ 2007 May, 34:1188-1193.

41. Shapiro SS, Wilk MB: An Analysis of Variance Test for Normality (Complete Samples). Biometrika. Vol. 52, No. 3/4. London, UK: Biometrika Trust; 1965:591-611.

42. Verbeke G, Molenberghs G: Linear Mixed Models for Longitudinal Data. New York, NY, USA: Springer; 2000:201-230.

43. Royston P: Multiple imputation of missing values. In The Stata Journal, Volume 4, Number 3. College Station, TX, USA: Stata Press; 2004:227-241.

44. Souberbielle JC, Prié D, Courbebaisse M, Friedlander G, Houillier P, Maruan


D status. Ann Endocrinol (Paris) 2008 Dec, 69:501-510.

\section{doi:10.1186/1745-6215-15-117}

Cite this article as: Cecchetti et al:: Efficacy and safety of pamidronate in Modic type 1 changes: study protocol for a prospective randomized controlled clinical trial. Trials 2014 15:117

\section{Submit your next manuscript to BioMed Central and take full advantage of:}

- Convenient online submission

- Thorough peer review

- No space constraints or color figure charges

- Immediate publication on acceptance

- Inclusion in PubMed, CAS, Scopus and Google Scholar

- Research which is freely available for redistribution 